\title{
The Concept of Cyber-Physical Networks of Small and Medium Enterprises under Personalized Manufacturing
}

\author{
Sebastian Saniuk ${ }^{1, *(D)}$ and Sandra Grabowska ${ }^{2, *(D)}$ \\ 1 Department of Engineering Management and Logistic Systems, University of Zielona Gora, \\ 65-417 Zielona Gora, Poland \\ 2 Department of Production Engineering, Silesian University of Technology, 40-019 Katowice, Poland \\ * Correspondence: s.saniuk@wez.uz.zgora.pl (S.S.); sandra.grabowska@polsl.pl (S.G.)
}

Citation: Saniuk, S.; Grabowska, S. The Concept of Cyber-Physical Networks of Small and Medium Enterprises under Personalized Manufacturing. Energies 2021, 14, 5273. https://doi.org/10.3390/ en14175273

Academic Editor: Marko Mladineo

Received: 6 June 2021

Accepted: 24 August 2021

Published: 25 August 2021

Publisher's Note: MDPI stays neutral with regard to jurisdictional claims in published maps and institutional affiliations.

Copyright: (c) 2021 by the authors. Licensee MDPI, Basel, Switzerland. This article is an open access article distributed under the terms and conditions of the Creative Commons Attribution (CC BY) license (https:// creativecommons.org/licenses/by/ $4.0 /)$.

\begin{abstract}
The era of Industry 4.0 is characterized by the use of new telecommunications ICT technologies and networking of the economy. This results in changes both in the way businesses operate and in customer expectations of products offered on the market. The use of modern ICT technologies has made it possible to create cyber-physical systems based on intelligent machines and devices that communicate with each other in real time and allow the integration of resources from different companies to carry out joint production projects. Today's consumer expects products tailored to their needs and expectations. These expectations can be met by leveraging the potential of highly specialized manufacturing service companies centered around e-business platforms. The article presents the results of research using bibliometric analysis and the results of surveys conducted among small and medium-sized enterprises. The concept of e-business platforms supporting rapid prototyping of temporary networks of companies capable of manufacturing personalized products in the environment of Industry 4.0 is presented. The task of the platform is to integrate a customer expecting personalized production with a network of companies having adequate production resources.
\end{abstract}

Keywords: cyber-physical networks; Industry 4.0; small and medium enterprises; personalization; servitization

\section{Introduction}

The Fourth Industrial Revolution introduces new changes in industry, economy and society [1]. Companies operating in today's market are beginning to understand the need for change, especially in the use of modern communication technologies and building a competitive advantage on the market through innovative action. The combination of industrial technologies with modern information and communication technologies (ICT) is the basis of concept proposed by German experts called Industry 4.0 (I 4.0) [2]. This concept is the result of the need to increase the level of industrial production in Western Europe (independence from production coming from the markets of the Middle East) on the one hand, and on the other hand the opportunities offered by the process of digitization and networking of the economy [3]. The Industry 4.0 concept is understood as a joining of intelligent resources and enterprise systems, as well as the introduction of changes in production processes' management which are able to increase production efficiency and flexibility and guarantee a high level of production personalization [4].

Industry 4.0 is called the Fourth Industrial Revolution and is understood as using intelligent technologies in companies and a new approach to people's lives in which mobile devices play an important role in communication. Social networks and unlimited access to information increase consumers' awareness, which results in their growing requirements from products offered on the market [5]. In this case, a modern and innovative approach is needed in the production management of both the enterprise and the network of enterprises that will radically increase flexibility, productivity and customer orientation [6]. According 
to Reischauer, the Industry 4.0 concept is understood as "policy-driven innovation discourse in manufacturing industries that aims to institutionalize innovation systems that encompass business, academia, and politics. This view clarifies the core identity of Industry 4.0, the intended outcome of Industry 4.0, and the stability of this intended outcome" [7].

Today's customers expect tailor-made products, according to their personal preferences and needs. They expect an impact on the configuration of manufactured products, but at the same time they require a price similar to the products offered in mass production $[8,9]$. Products are expected to be better tailored to the needs of consumers and even involve them in the design and manufacturing of products through B2C systems. There is a growing demand for personalized products [10].

This means that there is a need for changes in the functioning of modern companies, which must change the business model and focus on the development of service offerings as a complement to the product offerings. In the organization and management sciences, more and more attention is being paid to the importance of services in the production process of goods. Adding services to the modus operandi of modern companies in order to create additional value for the customer is defined as "servitization" [11] or "service infusion" $[12,13]$. Servitization helps build better customer-manufacturer interaction, makes better use of resources, and provides networking opportunities [14]. This may particularly concern the sector of small and medium enterprises which, unlike large enterprises with great development potential, see an opportunity for development in the conditions of Industry 4.0 in cooperation and narrow specialization [15]. Creating network forms of cooperation is not only an excellent opportunity for manufacturing personalized products and services, but also for dynamizing business models within the concept of Industry 4.0 and a chance to increase the competitiveness of enterprises. The idea of a production network means generating common production orders using fully automated processes of individual network partners, where communication takes place via the internet, and the necessary data is stored in the cloud (cloud computing). The cooperation within the network covers the whole chain of creating value for the customer-from designing the product, through its manufacturing, delivery and use together with offering complementary services (servitization). In the literature, this type of network is also called "Innovative Manufacturing Network of Smart Factories" [16], "Virtual Enterprise Network" [17], "Modular Production Networks" [18] or "Network of Enterprises" [19]. However, focusing on services for networks and development of own know-how requires solving a number of problems resulting from a lack of business models of cyber physical networks of small and medium enterprises [20].

Hence, there is a need for research in the development of business models and concepts for the formation of networks using intelligent resources for the realization of specific personalized products in interaction with the customers. The article emphasizes the need to create e-business platforms that bring together, on the one hand, enterprises offering services and resources for joint implementation of customized production and, on the other hand, customers expecting products tailored to their needs. The main aim of the article is to present the concept of an e-business platform supporting the rapid prototyping of temporary enterprise networks capable of producing personalized products in the Industry 4.0 environment. Furthermore, the article proposes a concept of a methodology for rapid network prototyping that guarantees personalized production orders' execution according to customer specifications. In the paper the following hypothesis: "The organization of e-business platforms of small and medium-sized enterprises will allow the integration of enterprise resources for the formation of cyber-physical networks under the conditions of the fourth industrial revolution" is considered.

\section{Challenges of the Fourth Industrial Revolution-State of Research}

Industry 4.0 is based on the application of intelligent machines, robots, means of transport and equipment within the cyber-physical system, which contains all activities of product development (product conceptualization, virtual documentation creation, virtual 
designing, 3D model printing, laboratory and industrial testing, modelling and simulation and lastly production in the real environment) [21]. In addition, the Industry 4.0 concept uses advanced computer-aided systems for design, production management, logistics, sales, service and recycling of products. Dynamic integration of intelligent and autonomous modules of the entire process of production preparation, production and delivery of the product to the customer takes place using IoT technology and information stored in big data and cloud computing. At the same time, a high level of high-efficiency production processes and the meeting of customer expectations is ensured [22]. The Industry 4.0 concept is aimed at significantly improving production efficiency by better using the available resources of enterprises within network cooperation and supply chains [23-25].

Industry 4.0 means the technical integration of all components of cyber-physical systems (CPS) in production and logistics processes through using the Internet of Things (IoT) and the Internet of Services (IoS) [26]. The Industry 4.0 concept requires new business models, reorganization of service and work processes and changes in value chains [27-29].

Under the conditions of the Fourth Industrial Revolution, there is a shift in the manufacturing paradigm towards customized production [30]. The need for customer orientation and offering customers highly personalized products at low prices means the need to change the existing strategies of enterprises. Successively, there is a greater level of interaction between the producer and the customer. Customers are more and more often involved in the creation and even final assembly of a product (e.g., IKEA). In terms of personalization, there are several basic dimensions [31]:

1. One-customer market-personalization is implemented at the individual level so that the customer feels that they are the exclusive or preferred recipient of the service or product.

2. Mass effectiveness-mass customized products are not completely new, as in the case of craft production. In this model, the idea is to customize the product to individual preferences, but with limited fulfillment costs [32].

3. Customer co-creation-companies in today's economy are forced to continually adapt due to increasingly complex and turbulent market conditions. Customer involvement in the design process should not be considered in terms of cost minimization but the chance to obtain higher value. Personalization, in this case, means active interaction with customers. In this case, creating new experiences and building customer satisfaction is more important than just creating a physical product [33].

4. User experience-producers should better understand the hidden needs of the customers instead of the standard exploration of the market potential. Personalization requires that the product be adaptable and configurable in every dimension, i.e., basic structure, design or packaging. It means better meeting the expectations of the individual preferences of the customer [34].

5. Customer-centric companies mean a personalized approach to production. By better integrating the supply chain with the customer, it is possible for the customer to design products online. A highly flexible supply chain will allow for unit production, but on an industrial scale in real-time. This means adopting a production strategy to order, which will lead to very short production lead times and the use of machines with short changeover times [35]. The supply of raw materials and semi-finished products will be based on demand forecasts derived from the demand. Machines will be designed to minimize setup times to accommodate changes in demand, batch sizes, specifications and other parameters [36].

Industry 4.0, by offering incredible technological developments, makes the boundaries between products and services increasingly blurred, enabling a company to transform from a product-based to a service-oriented approach [37]. Servitization represents a significant change in a company's business model, making service activities an engine of growth for the company. The infusion of services takes place when the importance of the services offered increases in relation to the product offer [38]. 
The concept of servitization usually encompasses enterprises that produce goods to which services are additionally provided. In manufacturing companies, it involves the development and delivery of new services or complex systems that integrate the goods and services provided (product and service solutions). The manufacturing enterprise is moving from exchanging goods with the customer to providing complex solutions [39]. For manufacturing companies, servitization implies a significant change in the perception of the business being run and the vision of its future shape. It is about shifting from a model that focuses on the physical, one-off product sold (possible repairs) to one that relies on regular services around that product [40]. With increasingly complex, high-tech equipment, customers are relying more than ever on their product vendors for expert service. Instead of focusing solely on selling a product, manufacturers are reinventing their strategy to meet the growing needs of customers, resulting in the sale of an entire service system around the product.

Servitization requires significant changes in many areas of a company's operations, and often requires a change in its business model. The product must be seen as a platform for providing a service. It must be accompanied by solutions that customers want. Indeed, these solutions are often captured in product-service systems and product-service combinations [41]. Customers only derive value from them if they actually receive the service-hence, the concept of use value. Servitization can be understood as the process of building revenue streams for producers from services. There are three levels of it that can be offered by producers [42]:

Level I: basic services-goods and spare parts, once they leave the factory, cease to be a problem for the manufacturer; at the same time, they also cease to be a source of revenue.

Level II: intermediate services-product repair, maintenance, overhaul, technical assistance, training, condition monitoring, and product maintenance provide manufacturers with a constant source of revenue.

Level III: advanced services-take after-sales services to a higher level of customer interaction, they are more relationship and customer-oriented than just selling and maintaining the product. In many cases, advanced services are provided in a subscription model in which the customer pays, for example, for hours of music listened to or pages printed.

The potential benefits of competing through advanced services are increased revenues and profits, better alignment with customer needs, enhanced product innovation, building new revenue streams, increased customer loyalty and setting higher barriers to competition [43]. Servitization is usually a subscription model and can be applied to most industries. It is a way to keep companies profitable and competitive in an era where the financial aspects of design and production are increasingly threatened by emerging markets and the life cycle of manufactured products, which is expected to lengthen due to environmental considerations. The need to include additional services, including consulting, is to improve the efficiency and profitability of the company [44]. Producing personalized products and incorporating services into their offerings is designed to meet customer needs $[45,46]$.

\section{Materials and Methods}

Bibliometric analysis and survey research on a selected group of Polish small and medium-sized enterprises were used to prove the need for research in the field of organization of e-platforms and business models of cooperation of small and medium-sized enterprises within cyber-physical networks.

Bibliometric analysis is a method used to observe the development of science, manifested, inter alia, by creating a network of research connections and the emergence of new, multidisciplinary fields of science. It allows you to identify the internal logic of the development of science [47]. The use of this method in the article made it possible for the reliable assessment of the research results to date and the number of publications and quotations in the analyzed area of research. The bibliometric analysis was conducted within the systematic literature review (SLR) steps [48]. They focus on classification of research 
contributions and subjective criteria for selecting papers. The search for scientific publications was conducted using the Web of Science (WoS) core collection and Scopus. Based on the methodology adopted in the study, the following steps were proposed: planning, implementation and reporting (Figure 1).

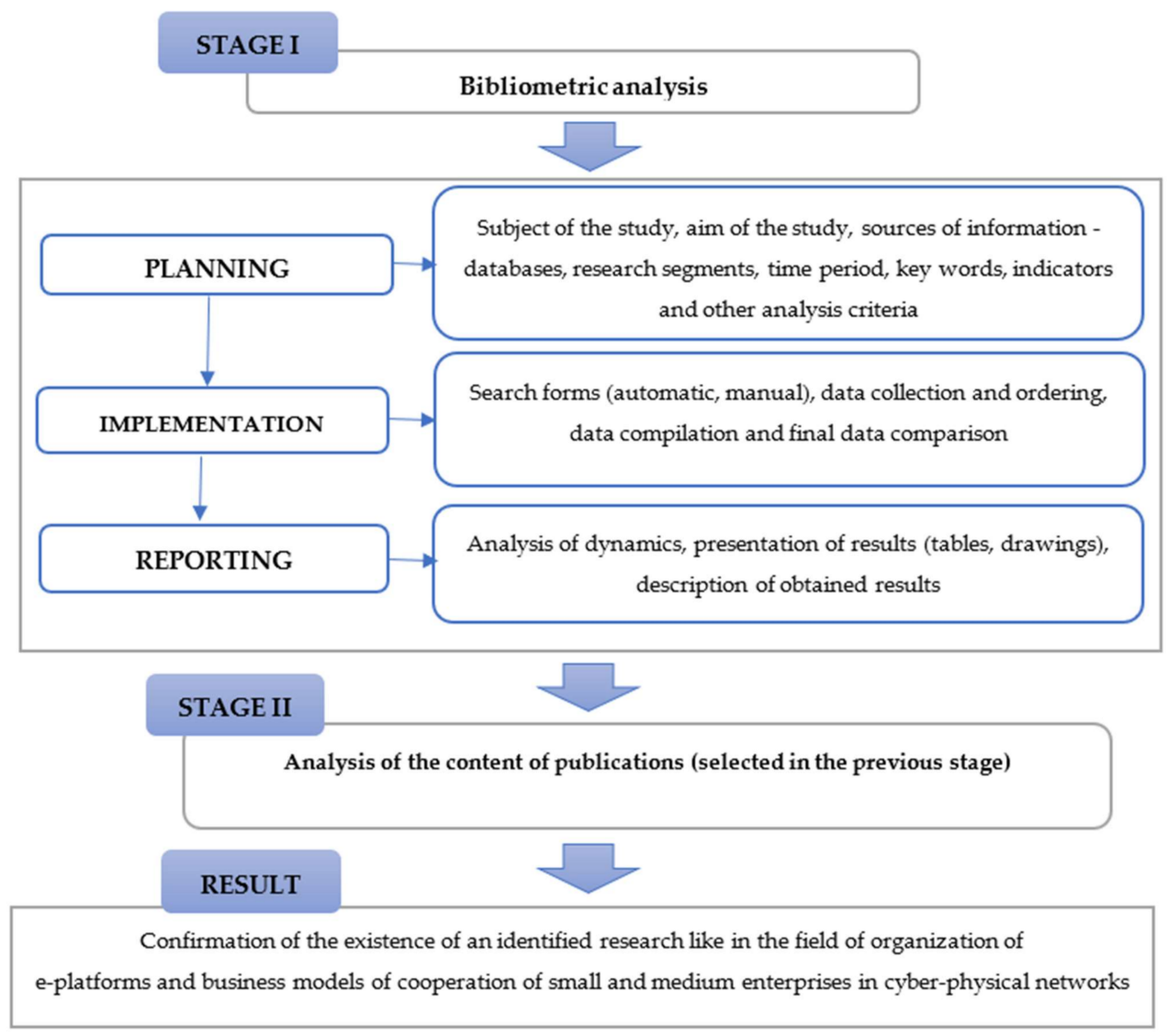

Figure 1. Bibliometric analysis based on methodology SLR. Source: own study.

The search was divided into three stages, each of which led to specific results, thereby increasing knowledge of industrial networks, SME and Industry 4.0. The different stages of the search along with the results they led to are shown in Figure 2.

The bibliometric analysis was intended to provide answers to the following questions:

1. Do authors dealing with industrial networks link this concept to Industry 4.0?

2. Do authors studying the SME sector describe the implementation of Industry 4.0 for this sector?

3. Do the authors dedicate industrial networks to SME?

Furthermore, the research material consisted of the results of a pilot survey conducted among Polish production enterprises from the SME sector. The conducted research concerned small and medium-sized production enterprises representing the metalworking sector. The processes which characterized this sector involved shaping and reshaping metals to create useful objects, parts, assemblies, and different structures. The research was conducted in the period from September 2018 to January 2019. The research was carried out using the CAWI method (computer-assisted web interview), and 50 enterprises took part in the survey (the sample was purposive). All small and medium enterprises agreed to fill the questionnaire and participated in the survey. The only criterion for selecting companies for the study was their size and sector of industry (production). The questionnaire was validated. The pilot surveys were conducted among 15 experts of production management. The questionnaire was revised with their comments. The questionnaire consisted of 12 questions. For the presentation of the results, several answers were selected 
that identified expectations and barriers related to the introduction of the Industry 4.0 concept and future cooperation of small and medium-sized enterprises. The main purpose of the survey was to demonstrate the need to develop the concept of rapid prototyping of cyber-physical production networks and the terms of cooperation within the network proposed in the article.

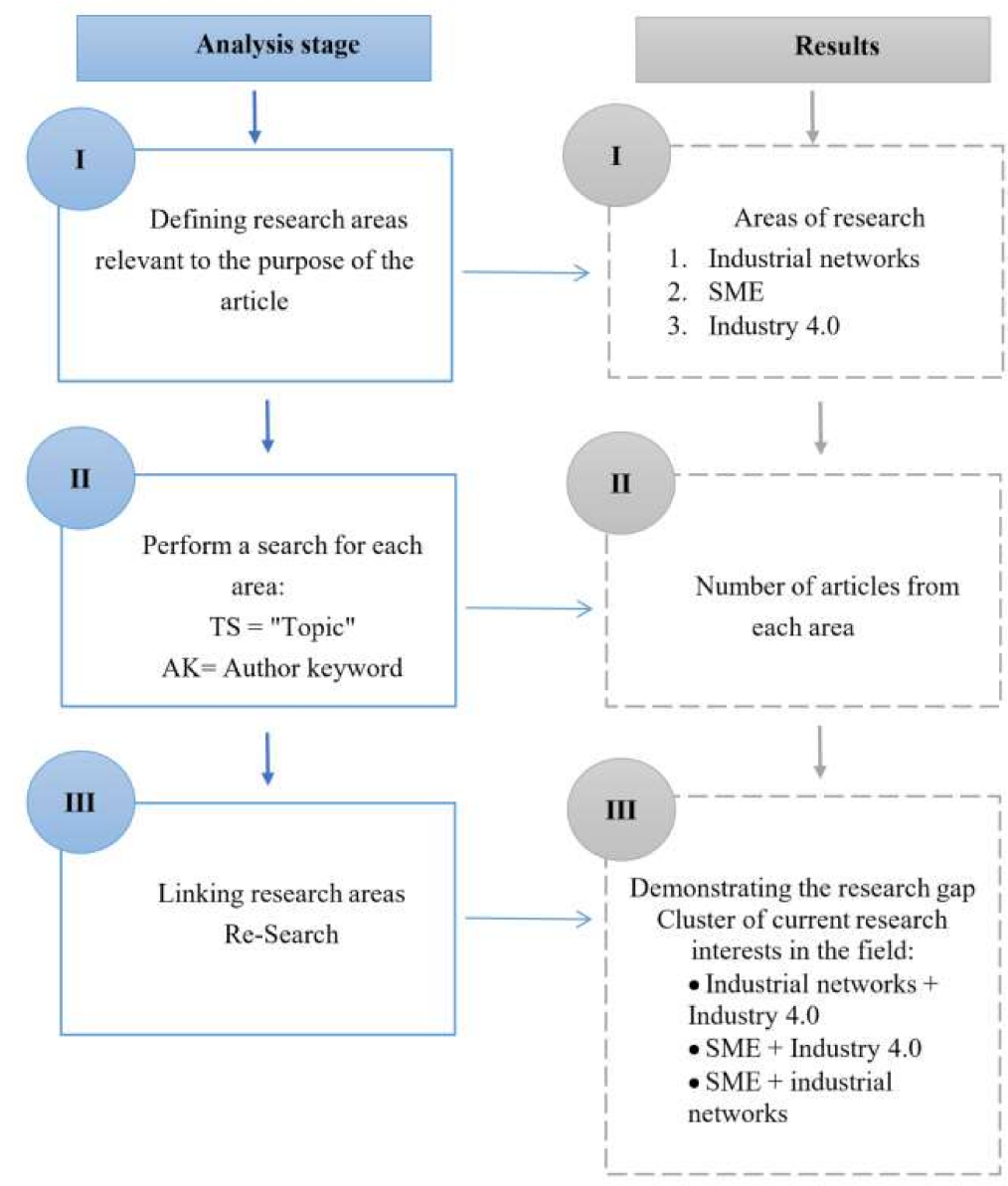

Figure 2. Search stages with results. Source: own elaboration.

\section{Results}

\subsection{Bibliometric Analysis-Results}

The body of knowledge related to SME research, industrial networks and Industry 4.0 is spreading significantly. The bibliometric analysis focused precisely on these three thematic/research areas. The focus was exclusively on academic articles, published between 1990 and 2020, in English. The beginning of the search period was defined as 1990, as this was the beginning of the Third Industrial Revolution, in which automation played a major role, enabling industrial networks.

For each research area, articles were searched under the category "Topic" (TS), which includes title, abstract, keywords defined by the authors; and "KeyWords Plus" (words and phrases extracted from the titles of cited articles). This allowed us to show the number of publications from each area. In the further part of the analysis, the search was narrowed down to articles in which the authors indicated as keywords (AK): industrial networks, SME and Industry 4.0, which guarantees the concentration of the article around this specific topic. The research areas were then combined to see how many articles were published in relation to "industrial networks AND Indsutry 4.0", "SME AND Industry 4.0", and "SME AND industrial networks". Detailed search data are included in Table 1. 
Table 1. Detailed search data from Web of Science and Scopus databases.

\begin{tabular}{|c|c|c|}
\hline & \multicolumn{2}{|c|}{ Database } \\
\hline & Web of Science & Scopus \\
\hline Year range & 1990-2020 & 1990-2020 \\
\hline Languages & English & English \\
\hline Type of document & Article & Article \\
\hline Field Tags: & \multicolumn{2}{|c|}{ Number of articles } \\
\hline & "Industrial networks" & \\
\hline TS = "industrial networks" & 432 & 836 \\
\hline $\mathrm{AK}=$ "industrial networks" & 114 & 387 \\
\hline \multicolumn{3}{|c|}{ "SME" } \\
\hline $\mathrm{TS}=$ "SME" & 8.995 & 22.111 \\
\hline $\mathrm{AK}=$ "SME" & 1.990 & 8.647 \\
\hline \multicolumn{3}{|c|}{ "Industry $4.0 "$} \\
\hline TS = Industry 4.0 & 5.371 & 3.877 \\
\hline $\mathrm{AK}=$ Industry 4.0 & 1.220 & 2.615 \\
\hline \multicolumn{3}{|c|}{ Advanced Search } \\
\hline TS = "industrial networks" AND “Industry 4.0" & 22 & 30 \\
\hline $\mathrm{AK}=$ "industrial networks" AND "Industry 4.0" & 2 & 7 \\
\hline $\mathrm{TS}=$ "SME" AND “Industry 4.0" & 44 & 138 \\
\hline $\mathrm{AK}=$ "SME” AND “Industry 4.0" & 11 & 55 \\
\hline $\mathrm{TS}=$ "SME" AND "industrial networks" & 5 & 16 \\
\hline $\mathrm{AK}=$ "SME" AND "industrial networks" & 0 & 2 \\
\hline
\end{tabular}

Of the three research areas searched, the largest group were articles relating to small and medium enterprises (WoS-TS:8.995, AK: 1.990; Scopus-TS: 22.111, AK:8.647). A smaller group were articles on Industry 4.0 (WoS-TS:5.371, AK; 1.220; Scopus-3.877; AK: 2.615). The smallest group was the articles from the field of "industrial networks" (WoS-TS: 432, AK: 114; Scopus-TS: 836, AK: 387).

Through the bibliometric analysis, it was found that industrial networks are combined with Industry 4.0, which is due to the fact that Industry 4.0 technologies are dedicated to this type of collaboration. Although the research area of SMEs is the largest, the issues of industrial networks and Industry 4.0 are rarely addressed in relation to SMEs; this indicates a definite research gap.

The final stage of the bibliometric analysis was a qualitative analysis of the articles that were extracted during the advanced search. It provided information-what issues are addressed by their authors. Thus, for the search:

- $\mathrm{AK}=$ "industrial networks" AND "Industry 4.0" (2 and 7 articles)—the following issues were identified: Data management, teaching and learning, internet of things, Blockchain, Cybersecurity, Digital twin, Digitalization, Supply chain, Command and control, covert channel, data exfiltration, stealth attacks, Distributed Systems, Internet of Things, manufacturing, data management, Performance analysis.

- $\quad \mathrm{AK}=$ "SME" AND "Industry 4.0" (11 and 55 articles) — the following issues were identified: production control, smart manufacturing, innovation, digitalization, automation, internet of things, simulation and modeling, e-Services, Supply Chains, Business Model, Mass customization, innovation, Internet of things, Cyber physical systems.

- $\quad \mathrm{AK}=$ "SME" AND "industrial networks" (0 and 2 articles) - the following problems were identified: cluster, collaboration, Productivity.

\subsection{Results of a Survey of Small and Medium-Sized Enterprises}

On the basis of the survey, key problems and expectations of selected companies were identified, which include the implementation of the Industry 4.0 concept in their strategy. On the one hand, the surveyed companies plan to adapt to Industry 4.0 technology in the future, and on the other hand, they do not have a strictly developed implementation plan ( $92 \%$ of respondents). Interesting from the point of view of the concept proposed 
in the article are the results concerning the expectations of SMEs that can support the implementation of the Industry 4.0 concept (Figure 3):

- Professional IT systems (platforms) to support networking of enterprises ( $80 \%$ of respondents).

- Business models dedicated for network cooperation of SMEs (72\% of respondents).

- Training on how to implement Industry 4.0 (67\% respondents).

- European programs supporting the Industry 4.0 technologies' implementation ( $55 \%$ respondents).

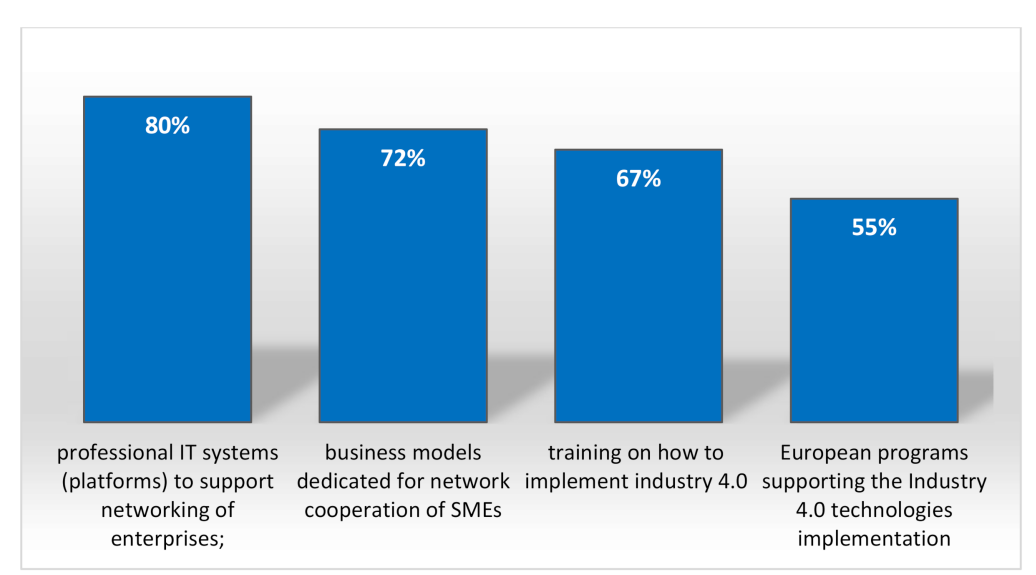

Figure 3. Expectations of SMEs that can support the implementation of the Industry 4.0 concept. Source: own elaboration.

They also indicate the main concerns related to the implementation of Industry 4.0 technology (Figure 4 ):

- High consulting costs in the field of new technologies (78\% respondents).

- Low level of return of investment (75\% respondents).

- Lack of qualified employees in the field of new technologies (67\% of respondents).

- Lack of knowledge about technologies dedicated to Industry 4.0 (65\% respondents).

- Problems with cooperation within networking (55\% respondents).

- Low level of automation and digitization of production ( $45 \%$ respondents).

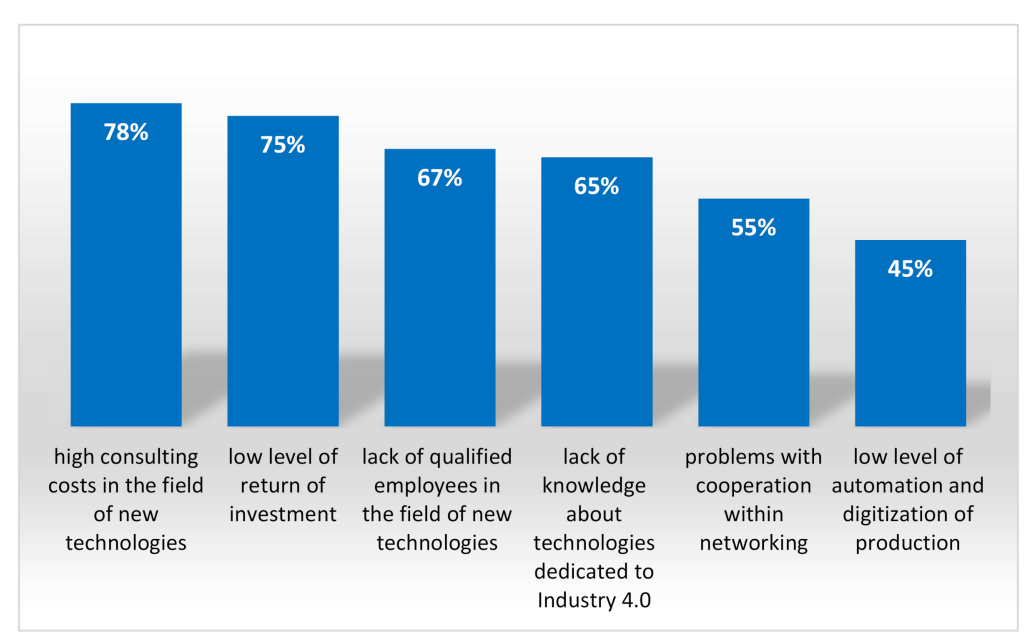

Figure 4. The main concerns of the Industry 4.0 technologies' implementation. Source: own elaboration.

Moreover, the surveyed companies, in general, are concerned about networking. The main problems with network cooperation were indicated as follows (Figure 5):

- Low level of cybersecurity for network cooperation (79\% respondents).

- Lack of effective business models for the cooperation of small and medium enterprises (72\% respondents).

- Logistical problems (67\% of respondents). 
- Disloyalty of network partners (45\% of respondents).

- Difficulties in searching for partners for the networks (41\% of respondents).

- Problem with co-responsibility for product quality (34\% of respondents).

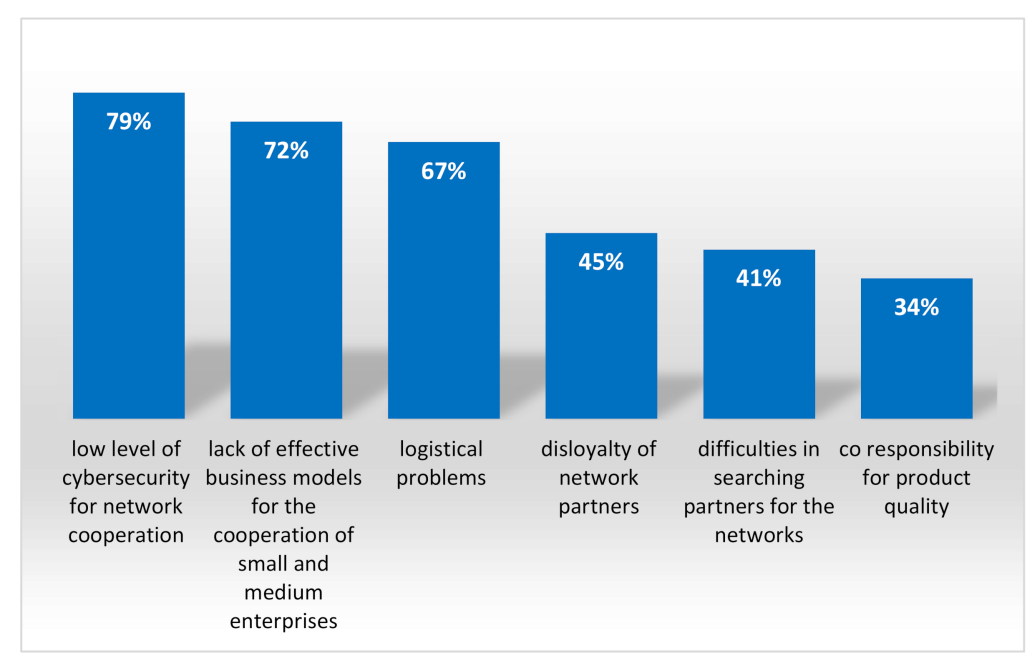

Figure 5. Main problems with network cooperation. Source: own elaboration.

\section{Discussion}

\subsection{Business Model of the Network of Cooperating Enterprises of Industry 4.0}

The ongoing development of a knowledge-based economy expressed in an intensive transfer and diffusion of innovations has a significant impact on changes in business models and business processes [49]. New forms of competitiveness and cooperation are emerging. This means that today's enterprise must abandon the patterns of the past and move from the old rules of operation envisioned for a resourceful enterprise to the formula of an intelligent, virtual and networked enterprise. The creation of network forms of cooperation is an excellent opportunity to dynamize business models within the concept of Industry 4.0 and a chance to increase competitiveness of enterprises [50]. This is confirmed by the results of bibliometric studies, which show that the technologies of Industry 4.0 enable and even facilitate and intensify the establishment of cooperation between companies within industrial networks. This is also confirmed by research among enterprises that confirms the need for cooperation throughout the implementation of the Industry 4.0 concept. Surveyed enterprises expect support in the field of European programs supporting the Industry 4.0 technologies' implementation and business models defining the terms of cooperation.

Today's economies are characterized by turbulent markets and globalization. This means for enterprises permanent changes and an intense increase in competition. There is an intensive development of technologies enabling the networking of the economy, greater integration of supply chains and cooperation of enterprises. The success of an enterprise is determined by access to real-time data and unlimited communication in a virtual environment [51]. The enterprise in the Industry 4.0 concept is seen as an intelligent module to be used in the value chain. The size of the enterprise is no longer important. In the cyber physical network, each enterprise offers various capabilities that can be used throughout the logistics chain within the Industry 4.0 concept. Modern enterprises should focus on the growth of the innovative technologies used, the level of highly qualified staff and the openness to unrestricted communication and networking. Meanwhile, the openness to unlimited communication using cloud computing, big data, and Internet of Things continues to grow rapidly. The key steps for companies to adapt to networking are shown in Figure 6. 


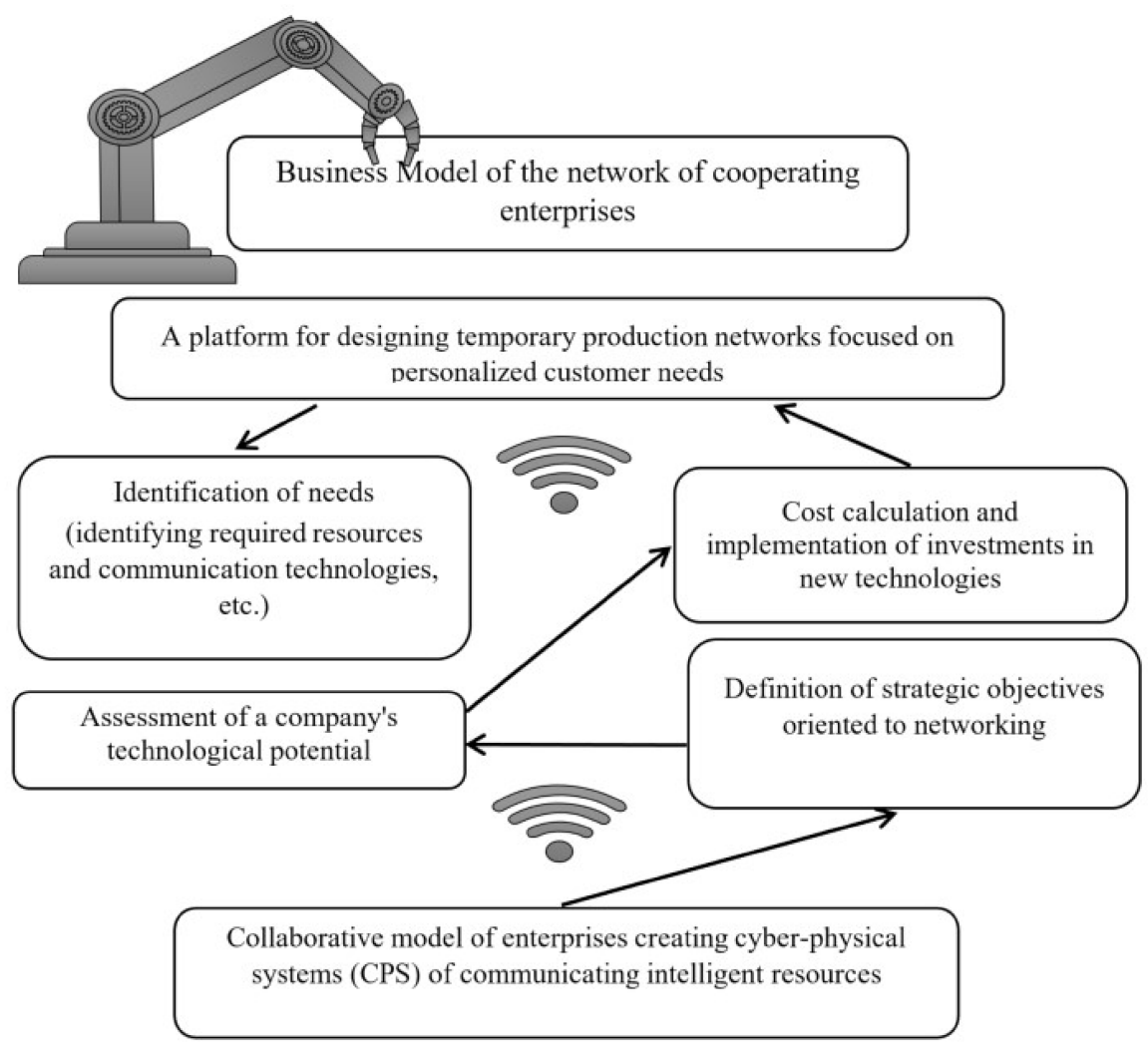

Figure 6. The key steps for companies to adapt to networking. Source: own elaboration.

The idea of a cyber-physical production network means the production order execution within shared intelligent resources of the individual network partners and communication between resources take place using real-time data and IoT [20]. An important feature of the cyber-physical network is that all network partners have access to the necessary information in real-time, regardless of the geographic location of the required resources. Thanks to the direct communication of intelligent resources, the partnership development is intensified based on combining key resources and competencies. Combining the resources of various enterprises into a network contributes to gaining a competitive advantage in the market and better orientation to the customer's needs [52].

However, in order to achieve the benefits of cooperation in the network, it is necessary to overcome the problems related to their creation, especially when the partners are enterprises from the SME sector. The process of selecting partners is complicated. Choosing a network partner requires checking, among others, partner's available production capacity, modern technology including intelligent resources, the quality level of services offered, experience, real-time communication ability, etc. [53]. Each of these areas has a major impact on the results of network creation. An equally important problem is the lack of trust, the need to invest in modern technologies and intelligent resources that are able to cooperate within the cyber-physical networks. This is especially true for the SME sector, which, due to high implementation and server costs, are only to a limited extent able to use advanced technologies. Similarly, the surveyed small and medium-sized enterprises indicate problems related to network cooperation and network forming. The most important ones include the low level of cybersecurity for network cooperation indicated by $72 \%$ of the respondents. More than half of the respondents emphasized logistical problems. Slightly less than half of the enterprises underlined difficulties in searching for partners for the networks and the problem of the disloyalty of network partners.

In the next stage, enterprises should reduce unnecessary infrastructure costs and decide on the key area of specialization in the network. This will allow for investments and, consequently, the development of narrow competencies and know-how that will be 
attractive to cyber-physical networks. Such an approach should guarantee a high level of use of available resources in the network and ensure the company's competitiveness in the market. The adoption of strategic goals focused on the implementation of modern technologies requires the next stage of transformation, consisting of the identification of intelligent resources and technologies required in CPS networks (German National Academy of Science and Engineering 2011). The last stage is to supplement the necessary resources and establish cooperation with the platform, the task of which is to organize temporary cyber-physical networks for the purpose of executing customer orders. Unfortunately, most of the surveyed small and medium-sized enterprises emphasized the high costs of consultancy in the field of new technologies (78\% of respondents) and a low level of return on investment (75\% of respondents). This can generate serious resistance to the successful implementation of network collaboration and the Industry 4.0 implementation.

The additional motivating factor to take the risk of investing in new technologies supporting the organization of cyber-physical networks is the positive experiences of enterprises, often presented in the literature. The partners cooperating in the network can offer products and services that better meet the needs of customers. The narrow specialization of enterprises, a high level of customization and the use of common resources will allow for the production of more complex and innovative products [54]. In addition, the functioning of enterprises in the network allows them to gain new experience and develop know-how. This is an advantage for both the enterprise and the network. The exchange of knowledge based on mutual relations increases the innovativeness of the offered products and services of the network [55]. Therefore, solving the problems of creating cyber-physical networks and cooperation of small and medium-sized enterprises is the basis for taking advantage of the opportunities offered by the implementation of the Industry 4.0 concept. The condition for the development of efficiently functioning networks is the development of a model of cooperation between enterprises. Created networks as CPS should ensure the collection, processing and access to data resulting from the implementation of physical material flow processes in the network. The implementation of joint production projects takes place using IoT and big data technologies used to enable unlimited communication of intelligent resources, at the same time with negligible participation of the supervising staff. The construction of the model, therefore, requires the identification of the conditions for the functioning of the enterprise in the cyber-physical production networks, the creation of temporary networks, scheduling and control of geographically dispersed intelligent resources or financial settlements of partners providing resources for production. First of all, the cyber-physical network requires an initial assessment of the technological potential, know-how, employees' competencies and resource sharing ability. This process is also focused on the production in the company [56]:

- The possibility of reducing the technological gap and ensuring technological readiness.

- Appropriate socio-technological potential.

- The ability to quickly implement innovations.

Cyber-physical production networks are characterized not only by a higher degree of functional integration but also by guaranteed easier access to the data generated by these systems (online) [57]. By networking and sharing data, enterprises are able to produce more efficiently and quickly meet customer needs. High flexibility is achieved by reducing the setup time it takes for machines to meet new requirements. Production tools can (in most cases) modify their operation on their own, adapting to new tasks-all it takes is the application of the appropriate command from the machine software [58]. This allows producers to execute small-batch production and even one or few products designed and produced as per the specification of customers, at the cost of standard mass production [56]. One of the key problems is network planning. Hence, the proposal of a concept based on building capability exchange platforms oriented towards personalized production. 


\subsection{The E-Business Platforms for Creating Cyber-Physical Industry Networks}

One of the ways of integrating small and medium enterprises and their resources to carry out joint ventures oriented to the needs of the modern customer is building e-business platforms. The need to organize e-platforms is indicated by as many as $80 \%$ of the surveyed enterprises. In contrast, the literature review conducted shows a distinct lack of such solutions for SMEs. The professional IT systems (platforms) to support the networking of enterprises are, on the one hand, to contact the customer specifying a personalized product and, on the other hand, to integrate the resources of enterprises involved in a cyber-physical network organized for the order execution. The platform is the interface between the customer and the producer. Through the proposed offer of both products and services, the customer can specify the product and even participate in the design of a new product online. The companies around the platform have the know-how to offer design, manufacturing and transport services to temporarily established networks, to which the resources of those companies are selected that are available at the time and guarantee the timely execution of the order. Figure 7 presents the e-business platform concept.

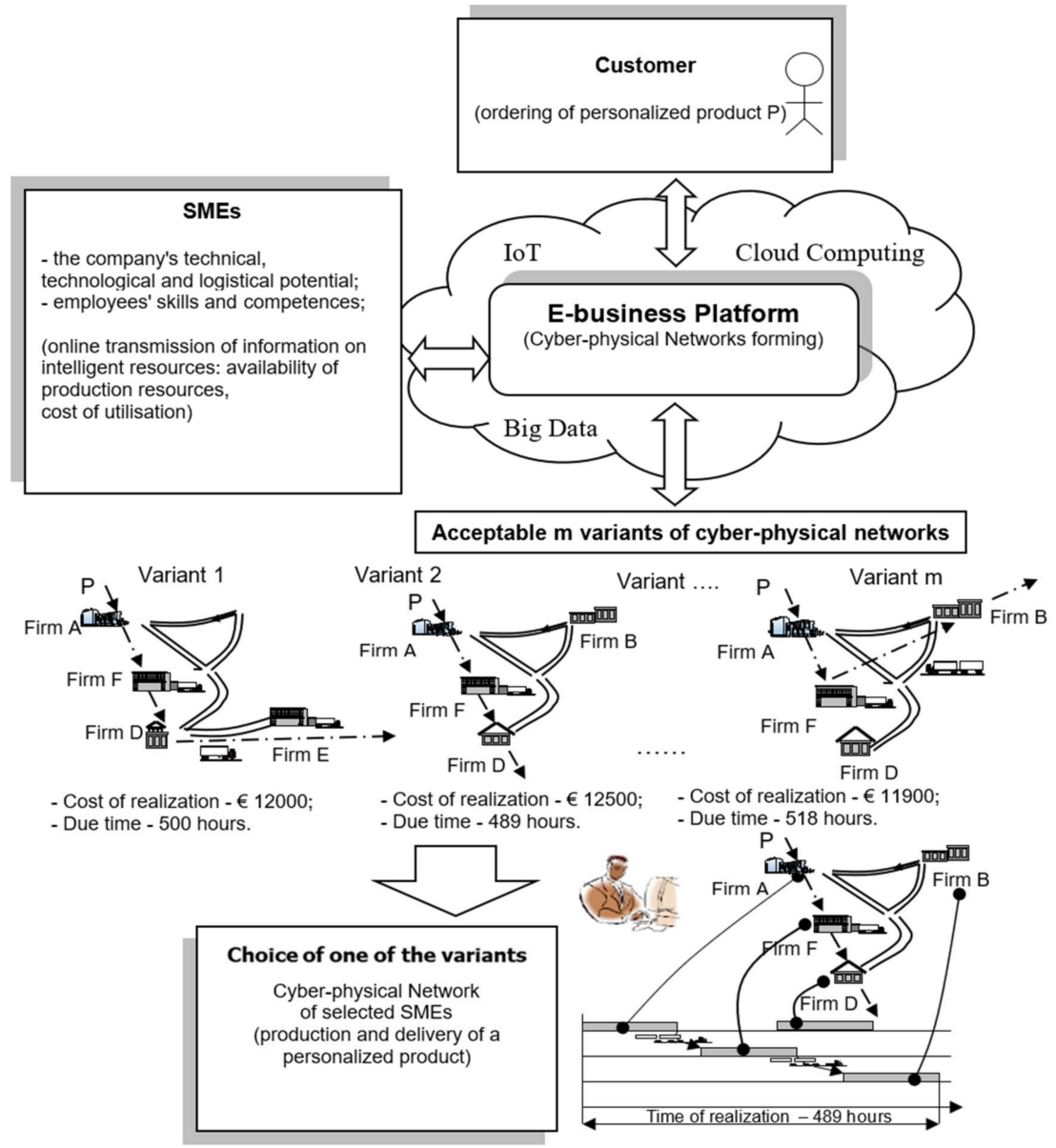

Figure 7. The e-business platform concept. Source: own elaboration.

In the Fourth Industrial Revolution era, the enterprise will be an intelligent module that is part of an integrated network of enterprises offering services to realize personalized products execution. Enterprises using the Industrial Internet of Things (IIoT) and cloud computing technologies provide real-time information about the status of intelligent resources (e.g., availability time, utilization cost, etc.) to the e-platform.

Overall, the platform is an excellent brokerage tool that, on the one hand, allows enterprises to plan tasks related to the execution of a new production order based on the specifications of the network customer, and on the other hand, allows them to collect and analyze data about the availability of enterprise resources. Based on the data provided 
by the resources, an appropriate algorithm based on the checking of sufficient conditions compares the generated plan for the execution of the order with the availability of resources offered by network partners. The result is a set of acceptable variants of cyber-physical networks and a detailed schedule of resource operation. From the acceptable variants, one variant is selected which has the shortest execution time or execution cost, which has a significant impact on the price. In the proposed approach, the customer decides which criterion is taken into account.

The methodology for planning a cyber-physical network is based on a sequence of checking of sufficient conditions. The proposed algorithm takes into account the constraints related to the availability of intelligent resources, the cost of their use, logistical constraints taking into account the distance between partners and the cost of transporting components in the physical material flow. In the proposed approach of cyber-physical networks' planning, three phases can be distinguished. The outline of the methodology is shown in Figure 8.

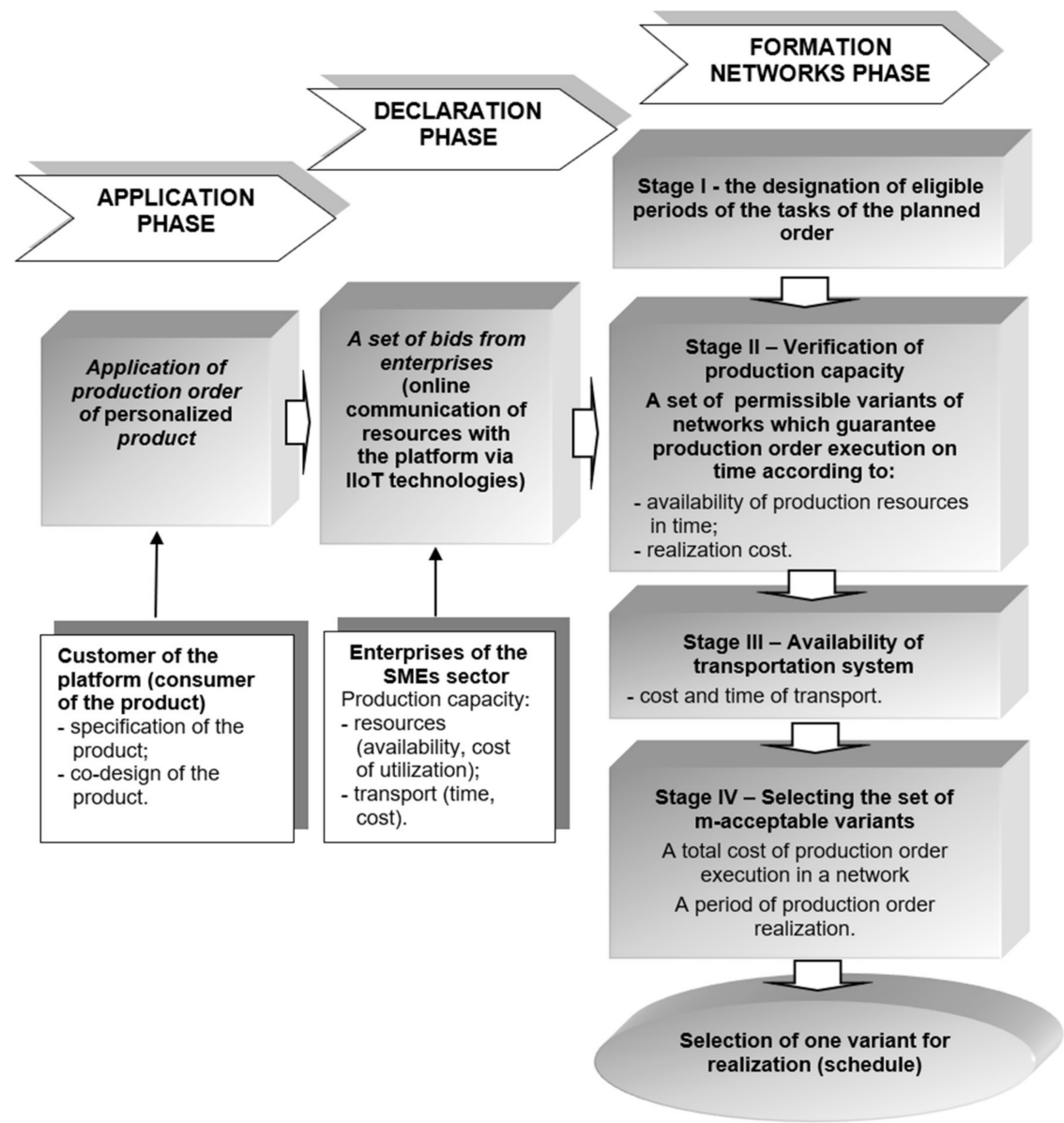

Figure 8. Outline of a platform planning methodology for cyber-physical networking. Source: own elaboration.

The first phase, called the "application phase", is the development of the design of the personalized product and the planning of the manufacturing operations that are associated with the production and delivery of the product to the customer. In this phase, the eplatform customer makes contact through an online e-commerce application and makes product specifications by selecting available product options and variants regarding shape, size, color or additional specific product features. In future, more advanced platform cases, the customer will be able to co-design the product through an intuitive computer-aided design (CAD) tool and create the product from scratch by selecting components from an available component library. After the product is accepted by the customer and sent for 
realization, the system will automatically create a plan of production operations selecting the appropriate manufacturing technology and production documentation.

In the next phase, the "declaration phase", the companies with adequate resources provide real-time information about the availability of production resources and information related to the cost of their use. The real-time transfer of information is possible by using the Industry 4.0 technologies (Industrial Internet of Things (IIoT), cloud computing and big data).

In the third phase, network variants are formed on the basis of the selection of resources for production operations, taking into account the succession of operations and logistical aspects related to the transportation of all materials and components during the production process for each of the acceptable network variants. At the same time, the cost of order execution is determined, which is the basis for determining the product price. As a result of this phase, a set of production networks representing a set of resources of different companies is obtained. Each variant is characterized by the time and cost of product realization. The final variant of the network is selected by the customer based on these two criteria. The price and lead time accepted by the customer means that the network is formed, and the production stages are launched in the individual enterprises of the network.

The proposed network formation approach uses a sequence of checks of sufficient conditions, the fulfilment of which guarantees the execution of the planned production order based on the analysis of data on available resources transmitted in real time from individual resources. The proposed planning approach allows for rapid prototyping of network variants. The proposed planning methodology is less labor and time consuming in contrast to the modeling and simulation methods and ad-hoc approach often used in such network planning cases. Nowadays, small and medium enterprises do not have effective methods for rapid network planning, especially in terms of partner selection and resource planning to fulfill customer-oriented orders. Hence, further development of the proposed concept seems to be a justified direction for further research in this area. The presented research results in the context of the considerations of other authors presented in the discussion confirm the correctness of the adopted hypothesis. The organization of e-business platforms of small and medium enterprises will allow the integration of enterprise resources in order to form cyber-physical networks in the conditions of the Industry 4.0 concept.

\section{Conclusions}

Based on the bibliometric analysis, industrial networks are often considered in scientific papers alongside Industry 4.0. This is due to the nature of the Industry 4.0 technologies' orientation towards networking the economy and the use of dispersed, intelligent resources along the entire value chain. Although the research area of SMEs is the largest, the issues of industrial networks including production networks and Industry 4.0 are rarely addressed in relation to SMEs, indicating a definite research gap.

The concept of Industry 4.0 achieves a high level of resource integration through unlimited communication of resources and integration of enterprises offering manufacturing services. Adding services to the core product offerings of enterprises to create additional value for the customer-defined as servitization—allows building better interaction between the customer and the producer. In addition, servitization makes better use of enterprise resources and provides opportunities for networking. This may particularly concern the sector of small and medium enterprises, which, in contrast to large enterprises with high development potential, see an opportunity for development in the conditions of Industry 4.0 in cooperation and narrow specialization.

Based on a conducted survey, the SME sector has indicated many expectations, e.g., need for professional IT systems (platforms) to support network cooperation, new business models and training in the area of Industry 4.0 implementation. The surveyed enterprises also indicate the key problems related to the implementation of the Industry 4.0 concept. 
The main problems concern network cooperation, e.g., difficulties in searching for partners for the networks, low level of cybersecurity for network cooperation, the disloyalty of network partners, lack of business models and business platforms. The other important concerns are as follows: high consulting costs in the field of new technologies, low level of return of investment lack of qualified employees in the field of new technologies and lack of knowledge about technologies dedicated to Industry 4.0. Focusing on services for the network and development of own know-how requires solving a number of problems resulting from the lack of business models of cyber-physical networks of small and medium enterprises and methods of establishing cooperation.

The concept of an e-platform supporting cyber-physical production network prototyping proposed in the paper is a way of integrating, on the one hand, the customer, who, in a particular case, becomes a consumer of the product after its purchase, with the producer. On the other hand, the e-platform can integrate small and medium enterprises or rather resources (machines, equipment, means of transport, employees) and services within the network. The servitization and organization of e-business platforms allow increasing the degree of utilization of cooperating companies' resources, thus increasing the level of resource productivity.

By providing a platform equipped with e-commerce sales applications through a web service and creating an intuitive interface for the customer, excellent integration between the future customer and distributed enterprises is achieved. The offered ability to specify the product by selecting available options or co-designing represents a significant improvement in real-time interaction with the customer.

Also noteworthy in the proposed approach is the involvement of the customer in the final selection of the network variant, thus influencing the price and time of production order execution.

The authors' future research focuses on developing detailed algorithms for prototyping network variants based on checking sufficient conditions based on information from intelligent resources of enterprises involved in the cooperation within the networks. The next step of research is developing a prototype e-business platform for small and medium industrial enterprises.

Author Contributions: The main activities of the team of authors can be described as follows: Conceptualization, S.S., S.G.; methodology, S.S., S.G.; software, S.S., S.G.; validation, S.S., S.G.; formal analysis, S.S., S.G.; investigation, S.S., S.G.; resources, S.S., S.G.; data curation, S.S., S.G.; writing—original draft preparation, S.S., S.G.; writing—review and editing, S.S., S.G.; visualization, S.S., S.G., supervision, S.S., S.G.; funding acquisition, S.S., S.G. All authors have read and agreed to the published version of the manuscript.

Funding: This research received no external funding.

Institutional Review Board Statement: Not applicable.

Informed Consent Statement: Not applicable.

Data Availability Statement: This study analyzed publicly available datasets available in the Web of Sience and Scopus database and quantitative data from companies.

Conflicts of Interest: The authors declare no conflict of interest.

\section{References}

1. Bauernhansl, T.; Hompel, M.; Vogel-Henser, B. Industrie 4.0 in Produkten, Automatisierung und Logistik; Springer Fachmedien: Wiesbaden, Germany, 2014.

2. Kagermann, H.; Wahlster, W.; Helbig, J. (Eds.) Recommendations for Implementing the Strategic Initiative Industrie 4.0: Final Report of the Industrie 4.0 Working Group. Industrie 4.0: Mit dem Internet der Dinge auf dem Weg zur 4. Industriellen Revolution; VDINachrichten: Frankfurt, Germany, 2011.

3. Zhou, K.; Liu, T.; Zhou, L. Industry 4.0: Towards Future Industrial Opportunities and Challenges. In Proceedings of the 2015 12th International Conference on Fuzzy Systems and Knowledge Discovery (FSKD), Zhangjiajie, China, 15-17 August 2015; pp. 2147-2152. 
4. Saniuk, S.; Grabowska, S.; Gajdzik, B. Personalization of Products in the Industry 4.0 Concept and Its Impact on Achieving a Higher Level of Sustainable Consumption. Energies 2020, 13, 5895. [CrossRef]

5. Holtgrewe, U. New technologies: The future and the present of work in information and communication technology. New Technol. Work Employ 2014, 29, 9-24. [CrossRef]

6. Bartosik-Purgat, M.; Ratajczak-Mrozek, M. Big Data Analysis as a Source of Companies' Competitive. Advantage: A Review. Entrep. Bus. Econ. Rev. 2018, 6, 197-215. [CrossRef]

7. Reischauer, G. Industry 4.0 as policy-driven discourse to institutionalize innovation systems in manufacturing. Technol. Forecast. Soc. Change 2018, 132, 26-33. [CrossRef]

8. Yang, Z.; Jun, M. Consumer Perception of E-Service Quality: From Internet Purchaser and Non-purchaser Perspectives. J. Bus. Strateg. 2008, 25, 59.

9. Silveira, G.; Da Borenstein, D.; Fogliatto, F.S. Mass customization: Literature review and research directions. Int. J. Prduction Econ. 2001, 72, 1-13. [CrossRef]

10. $\mathrm{Hu}, \mathrm{S} . J$. Evolving paradigms of manufacturing: From mass production to mass customization and personalization. Procedia CIRP 2013, 7, 3-8. [CrossRef]

11. Vandermerwe, S.; Rada, J. Servitization of business: Adding value by adding services. Eur. Manag. J. 1988, 6, 314-324. [CrossRef]

12. Brax, S. A manufacturer becoming service provider: Challenges and a paradox. Manuf. Serv. Qual. 2005, 15, 142-155. [CrossRef]

13. Kowalkowski, C.; Gebauer, H.; Kamp, B.; Parry, G. Servitization and deservitization: Overview, concepts, and definitions. Ind. Mark. Manag. 2017, 60, 4-10. [CrossRef]

14. Vargo, S.; Lusch, R. Service-dominant logic 2025. Int. J. Res. Mark. 2017, 34, 46-67. [CrossRef]

15. Kliment, M.; Pekarcikova, M.; Trebuna, P.; Trebuna, M. Application of TestBed 4.0 Technology within the Implementation of Industry 4.0 in Teaching Methods of Industrial Engineering as Well as Industrial Practice. Sustainability 2021, 13, 8963. [CrossRef]

16. Veza, I.; Mladineo, M.; Gjeldum, N. Managing Innovative Production Network of Smart Factories. IFAC-PapOnLine 2015, 48, 555-560. [CrossRef]

17. Camarinha-Matos, L.M.; Afsarmanesh, H. Virtual Enterprise Modeling and Support Infrastructures: Applying Multi-agent System Approaches. In Proceedings of the ECCAI Advanced Course on Artificial Intelligence; Springer: Berlin/Heidelberg, Germany, 2001; pp. 335-364.

18. Sturgeon, T.J. Modular Production Networks: A New American model of Industrial Organization. Ind. Corp. Chang. 2002, 11, 451-469. [CrossRef]

19. Villa, A. Organizing a 'network of enterprises': An object-oriented design methodology. Comput. Integrated Manuf. Syst. 1998, 11, 331-336. [CrossRef]

20. Saniuk, S.; Saniuk, A.; Cagáňová, D. Cyber Industry Networks as an environment of the Industry 4.0 implementation. Wirel. Netw. 2019, 27, 1649-1655. [CrossRef]

21. Stock, T.; Seliger, G. Opportunities of Sustainable Manufacturing in Industry 4.0. Procedia Cirp. 2016, 40, 536-541. [CrossRef]

22. Goti-Elordi, A.; De La Calle-Vicente, A.; Gil-Larrea, M.; Errasti, A.; Uradnicek, J. Application of a Business Intelligence tool within the context of Big Data in a food industry company. Dyna 2017, 92, 347-353. [CrossRef]

23. Wang, L.; Törngren, M.; Onori, M. Current status and advancement of cyber-physical systems in manufacturing. J. Manuf. Syst. 2015, 37, 517-527. [CrossRef]

24. Zoubek, M.; Poor, P.; Broum, T.; Basl, J.; Simon, M. Industry 4.0 Maturity Model Assessing Environmental Attributes of Manufacturing Company. Appl. Sci. 2021, 11, 5151. [CrossRef]

25. Vane, J.; Frantisek, K.; Basl, J. Engineering companies and their readiness for Industry 4.0. Int. J. Product. Perfomance Manag. 2021, 70, 1072-1091. [CrossRef]

26. Jazdi, N. Cyber physical systems in the context of Industry 4.0. In Proceedings of the 2014 IEEE International Conference on Automation, Quality and Testing, Robotics, Cluj-Napoca, Romania, 22-24 May 2014; pp. 1-4.

27. Grabowska, S. Smart Factories in the age of Industry 4.0. Manag. Syst. Prod. Eng. 2020, 28, 2. [CrossRef]

28. Grabowska, S.; Saniuk, S. Modern marketing for customized products under conditions of fourth industrial revolution. In Industry 4.0. A Glocal Perspective; Jerzy, D., Aleksandra, G., Eds.; Routledge: New York, NY, USA, 2021. [CrossRef]

29. Saniuk, S.; Grabowska, S. Challenges of business model concept of small- and medium-sized enterprise cooperation. In Industry 4.0. A Glocal Perspective; Jerzy, D., Aleksandra, G., Eds.; Routledge: New York, NY, USA, 2021. [CrossRef]

30. Lampel, J.; Mintzberg, H. Customizing Customization. Sloan Manag. Rev. 1996, 38, 21-30.

31. Zhou, F.; Ji, Y.; Jiao, R. Affective and cognitive design for mass personalization: Status and prospect. J. Intell. Manuf. 2013, 245, 1047-1096. [CrossRef]

32. Kumar, A. From mass customization to mass personalization: A strategic transformation. Int. J. Flex. Manuf. Syst. 2007, 19, 533-547. [CrossRef]

33. Arora, N.; Dreze, X.; Ghose, A.; Hess, J.; Iyengar, R.; Jing, B.; Joshi, Y.; Kumar, V.; Lurie, N.; Neslin, S.; et al. Putting one-to-one marketing to work: Personalization, customization, and choice. Mark. Lett. 2008, 19, 305-321. [CrossRef]

34. Młody, M. Product personalization and Industry 4.0-Assessment of the rightness of the implementation of modern technologies in the manufacturing industry from the consumers' perspective. Ekon. Organ. Przedsiębiorstwa 2018, 3, 62-67.

35. Senanayake, M.; Little, T. Mass customization: Points and extent of apparel customization. J. Fash. Mark. Manag. Int. J. 2010, 14, 282-299. [CrossRef] 
36. Raddats, C.; Kowalkowski, C.; Benedettini, O.; Burton, J.; Gebauer, H. Servitization: A contemporary thematic review of four major research streams. Ind. Mark. Manag. 2019, 83, 207-223. [CrossRef]

37. Fatorachian, H.; Kazemi, H. A criticalinvestigation of Industry 4.0 in manufacturing: Theoretical operationalisation framework. J. Prod. Plan. Control Manag. Oper. 2018, 29, 633-644. [CrossRef]

38. Opresnik, D.; Taisch, M. The value of Big Data in servitization. Int. J. Prod. Econ. 2015, 165, 174-184. [CrossRef]

39. Baines, T.; Ziaee Bigdeli, A.; Bustinza, O.; Shi, V.; Baldwin, J.; Ridgway, K. Servitization: Revisiting the state-of-the-art and research priorities. Int. J. Oper. Prod. Manag. 2017, 37, 256-278. [CrossRef]

40. Baines, T.S.; Lightfoot, H.W.; Benedettini, O.; Kay, J.M. The servitization of manufacturing: A review of literature and reflection on future challenges. J. Manuf. Technol. Manag. 2009, 20, 547-567. [CrossRef]

41. Vendrell-Herrero, F.; Bustinza, O.F.; Parry, G.; Georgantzis, N. Servitization, digitization and supply chain interdependency. Ind. Mark. Manag. 2017, 60, 69-81. [CrossRef]

42. Coreynen, W.; Matthyssens, P.; Van Bockhaven, W. Boosting servitization through digitization: Pathways and dynamic resource onfigurations for manufacturers. Ind. Mark. Manag. 2017, 60, 42-53. [CrossRef]

43. Du, H.; Li, B.; Brown, M.A.; Mao, G.; Rameezdeen, R.; Chen, H. Expanding and shifting trends in carbon market research: A quantitative bibliometric study. J. Clean Prod. 2015, 103, 104-111. [CrossRef]

44. Strozzi, F.; Colicchia, C.; Creazza, A.; Noe, C. Literature review on the Smart Factory concept using bibliometric tools. Int. J. Prod. Res. 2017, 55, 6572-6591. [CrossRef]

45. Straka, M.; Malindzakova, M.; Trebuna, P.; Rosova, A.; Pekarcikova, M.; Fill, M. Application of extendsim for improvement of production logistics' efficiency. Int. J. Simul. Model. 2017, 16, 422-434. [CrossRef]

46. Trebuňa, P.; Pekarcikova, M.; Edl, M. Digital Value Stream Mapping Using the Tecnomatix Plant Simulation Software. Int. J. Simul. Model. 2019, 18, 19-32. [CrossRef]

47. Ziegler, B. Methods for Bibliometric Analysis of Research: Renewable Energy Case Study; Massachusetts Institute of Technology: Cambridge, MA, USA, 2009.

48. Miao, F.; Wang, G.; Jiraporn, P. Key supplier involvement in IT-enabled operations: When does it lead to improved performance? Ind. Mark. Manag. 2018, 75, 134-145. [CrossRef]

49. McAfee, A.; Brynjolfsson, E. Big data: The management revolution. Harv. Bus. Rev. 2012, 90, 60-68.

50. Birkel, H.S.; Veile, J.W.; Müller, J.M.; Hartmann, E.; Voigt, K.-I. Development of a risk framework for Industry 4.0 in the context of sustainability for established manufacturers. Sustainability 2019, 11, 384. [CrossRef]

51. Baraldi, E.; Gressetvold, E.; Harrison, D. Resource interaction in inter-organizational networks: Foundations, comparison and a research agenda. J. Bus. Res. 2012, 65, 266-276. [CrossRef]

52. Xu, L.D.; Duan, L. Big data for cyber physical systems in industry 4.0: A survey. Enterp. Inf. Syst. 2019, 13, 148-169. [CrossRef]

53. Napoleone, A.; Macchi, M.; Pozzetti, A. A review on the characteristics of cyber-physical systems for the future smart factories. J. Manuf. Syst. 2020, 54, 305-335. [CrossRef]

54. Rossit, D.A.; Tohmé, F.; Frutos, M. A data-driven scheduling approach to smart manufacturing. J. Ind. Inf. Integr. 2019, 15, 69-79. [CrossRef]

55. Schuh, G.; Potente, T.; Wesch-Potente, C.; Hauptvogel, A. Sustainable Increase of Overhead Productivity due to Cyber-PhysicalSystems. Procedia CIRP 2013, 19, 51-56. [CrossRef]

56. Cheng, G.; Liu, L.; Qiang, X.; Liu, Y. Industry 4.0 Development and Application of Intelligent Manufacturing. In Proceedings of the 2016 International Conference on Information System and Artificial Intelligence (ISAI), Hong Kong, China, 24-26 June 2016; pp. 407-410. [CrossRef]

57. Lee, J.; Bagheri, B.; Kao, H. Research Letters: A Cyber-Physical Systems architecture for Industry 4.0-based manufacturing systems. Manuf. Lett. 2016, 3, 18-23. [CrossRef]

58. Oks, S.J.; Fritzsche, A.; Möslein, K.M. An Application Map for Industrial Cyber-Physical Systems. Ind. Internet Things 2017, 62, 21-45. 